\title{
The impact of weekends on outcome for acute exacerbations of COPD
}

\author{
R. Barba*, A. Zapatero\#, J.E. Losa ${ }^{\mp}$, J. Marco ${ }^{+}$, S. Plaza ${ }^{\S}$, C. Rosado ${ }^{f}$ and J. Canora\#
}

\begin{abstract}
Differences in hospital staffing may influence outcomes for patients with acute conditions, including acute exacerbations of chronic obstructive pulmonary disease (COPD), depending on which day of the week the patients are admitted. This study was conducted to determine whether weekend admission increases the risk of dying in hospital.
\end{abstract}

We analysed the clinical data of 289,077 adults with acute exacerbations of COPD admitted to the hospital at any public centre in Spain, during 2006 and 2007. We analysed the following factors for their association with death rate: day of admission, demographics, medical history and comorbidity.

During the study period, there were 35,544 (12.4\%) deaths during admission in COPD patients. Weekend admissions were associated with a significantly higher in-hospital mortality (12.9\%) than weekday admissions (12.1\%) among COPD patients (OR 1.07 (95\% Cl 1.04-1.10)). The differences in mortality persisted after adjustment for age, sex and coexisting disorders (OR 1.05 (95\% Cl 1.02-1.08)). Analyses of deaths within 2 days after admission showed larger relative differences in mortality between the weekend and weekday admissions (OR 1.17 (95\% $\mathrm{Cl} 1.11-$ 1.23)).

We conclude that patients with acute exacerbations of COPD are more likely to die in the hospital if they are admitted on a weekend compared with a weekday.

KEYWORDS: Chronic obstructive pulmonary disease, mortality, weekend effect

A cute exacerbations of chronic obstructive pulmonary disease (COPD) are among the leading causes of morbidity and mortality in industrialised countries [1, 2]. $\sim 10 \%$ of all hospitalisations are either directly or indirectly attributable to COPD [3], and internal medicine [4] and respiratory wards care for many patients with this disease. Acute exacerbations of COPD requiring hospital treatment are a severe strain on health services and are responsible for at least two-thirds of the total cost of treating respiratory diseases in both Europe and the USA [5]. The acute exacerbation phase entails a substantial rate of hospital mortality [6]. The recognition of risk factors for mortality among patients hospitalised for COPD can be of crucial importance for curtailing cost and reducing mortality.

Several studies [7-12] concluded that weekend hospitalisation is associated with worse health outcomes. These studies are supported by the work of others [13, 14], which find a positive correlation across hospitals between annual average staff-to-patients ratios and quality of care. While the burden of disease and demand on health services is similar from one day to the next, at the weekend, there are staff shortages and reduced availability of services. Unfortunately, this might not be compensated for by increased care on subsequent days.

The weekend effect on COPD has been specifically studied in a recent Australian study [15] by a retrospective analysis of administrative data from public hospitals, analysing the 30-day inhospital mortality in 30,000 patients; no significant weekend effect was detected. However, in a Finnish study [2], COPD patients admitted at the weekend showed significantly higher mortality rates than those admitted on a weekday. We decided to use a bigger sample to confirm whether the weekend effect is present in Spain, because the Australian sample might not have been large enough to demonstrate this small but transcendent effect. We believe that even small differences in clinical outcomes between weekday and weekend admission of patients with COPD could translate into substantial numbers of deaths for this patient population due to the large number of patients hospitalised with COPD each year [3]. We decided to compare mortality rates among patients admitted with acute exacerbation of COPD at weekends with those admitted on weekdays.
AFFILIATIONS

${ }^{\star}$ Depts of Internal Medicine, Hospital Infanta Cristina, Parla,

\#Hospital Universitario de Fuenlabrada, Fuenlabrada,

"Hospital Universitario Fundación Alcorcón, Alcorcón,

+Hospital Clínico de San Carlos, ${ }^{\S}$ Hospital Severo Ochoa, Leganés, and

${ }^{f}$ Dept of Admission, Hospital Infanta Cristina, Parla, Madrid, Spain.

CORRESPONDENCE

R. Barba

Hospital Infanta Cristina

Avda 9 Junio no. 2

28981

Parla

Madrid

Spain

E-mail: raquel.barba@

salud.madrid.org

Received:

Jan 242011

Accepted after revision:

May 242011

First published online:

June 092011

European Respiratory Journa

Print ISSN 0903-1936

Online ISSN 1399-3003 


\section{MATERIAL AND METHODS}

The study included all patients admitted to all acute care hospitals of the Public Health Service through an emergency department in Spain between January 1, 2006 and December 31, 2007, with COPD as the primary reason for discharge. All elective admissions and elective transfers were excluded. Hospital discharge data were obtained from the basic minimum data set (CMBD). The CMBD contains sociodemographic and clinical data for each documented hospital admittance including: sex and age; primary and secondary diagnoses (according to the International Classification of Diseases, Ninth Revision, Clinical Modification (ICD-9-CM) code); primary and secondary procedures; admission and discharge status; length of stay; and hospital characteristics (group 1: <150 beds; group 2: 150-200 beds; group 3: 200-500 beds; group 4: 500-1,000 beds; and group 5: $>1,000$ beds). For every patient, a diagnosis-related group (DRG) was identified. DRGs are a way of classifying patient hospitalisations by diagnosis and procedure on the assumption that similar costs are expended on patients by using similar resources. The CMBD registry is compulsory for every patient admitted to a hospital of the Spanish National Health Service, a system that cares for $>90 \%$ of the country's population.

Cases were selected if they were discharged with the diagnosis of COPD (DRG code 88, COPD; 540, respiratory infections and inflammations with major complications; or 541, respiratory disorders except infections, bronchitis, asthma with major complications; DRG-AP.21 version). We also identified the primary diagnosis of COPD using the following ICD-9-CM codes in the primary diagnosis field: 491.0, 491.1, 491.9, 491.20, 491.21, $491.22,496,518.8,518.81$ and 518.9.

Consecutive patients were identified according to the day of the week in which they were admitted. The weekend was defined as the period between midnight on Friday and midnight on Sunday. All other times were defined as weekdays. These time frames were selected because of our confidence in the reliability of the code for day of the week. This convention has been used in other studies involving administrative databases $[8,10]$. Patients were divided into two groups: 1 ) those dying during the hospital stay, and 2) those either discharged or moved to other centres. Two outcomes of interest were considered: 1) early mortality, defined as that occurring within the first $48 \mathrm{~h}$ after admission, and 2) overall mortality, including deaths taking place at any time during the hospital stay.

Covariates included patient characteristics, the presence or absence of coexisting conditions (including acute respiratory failure, diabetes, hypertension, heart failure, chronic renal disease, anaemia, ischaemic heart disease, dementia, cancer, pneumonia, stroke and cigarette smoking). The Charlson comorbidity index (CCI) was computed for each patient $[16,17]$. This index reflects the number and importance of comorbid diseases, relies on ICD categories, and was used to adequately adjust for the severity of illnesses. The index, which has been adapted for use with administrative databases, values the presence of 19 medical conditions, with a scale of 1-6, and a total grade between $0-37$. An index value $>2$ is related to a mortality rate $>50 \%$ per year.

\section{Statistical analysis}

We compared differences in demographic characteristics and mortality between patients admitted on weekends and on weekdays using the Chi-squared test or the unpaired t-test. Control for confounding is critical to the attribution of effects when using administrative data. We examined potential confounders (age, sex, CCI and coexisting conditions) and applied the conventional criteria for statistical significance $(p<0.05)$. Multiple logistic regression models were used to account for confounding effects of patient demographics and coexisting conditions and complications. Subgroup analyses were performed for patients with principal diagnosis of COPD. An analysis of deaths within 1, 2, 3 and 4 days after admission, and the same day of admission was performed. Differences in mortality rates were expressed as odds ratios for death, where appropriate. p-values $<0.05$ (two-tailed) were considered statistically significant. All statistical analyses were performed using SPSS 15.0 (SPSS Inc., Chicago, IL, USA).

\section{RESULTS}

During the study period, there were 289,077 COPD admissions that came from an emergency department. The age of patients was mean \pm SD $73.94 \pm 13.2 \mathrm{yrs} ; 69.9 \%$ of the patients were male. The length of stay was $9.78 \pm 8.9$ days. The CCI value was $1.95 \pm 1.83$ (range $0-19$ ), and a CCI $\geqslant 2$ was present in $23.6 \%$ of the cases. COPD as a principal diagnosis was present in $132,465(42.3 \%)$ cases. Pneumonia $(26.5 \%)$ was the second principal diagnosis and embolism the third (2\%). Overall, $69,770(24.1 \%)$ of the patients were admitted on weekends, and $219,307(75.9 \%)$ on weekdays. There were no relevant differences in demographic characteristics between the patients admitted on weekends and those admitted on weekdays. There were small but statistically significant differences in several conditions, such as acute respiratory failure (more frequently in patients admitted on weekends), or cancer (more common in patients admitted on a weekday) (table 1). The median score on the comorbidity index was higher among patients admitted on a weekday, compared with those admitted on a weekend (1.96 versus 1.94; $\mathrm{p}=0.005)$.

The distributions of hospitalisations by the admission day of the week are shown in table 2. Monday was the most frequent day of admission for COPD (15.8\%) and Sunday the least frequent day $(11.7 \%)$. The proportion of weekend admissions differed from that which would be expected (two out of seven or $28.7 \%$ ). The real proportion of weekend admissions was $24.1 \%$.

\section{Mortality}

A total of 35,544 (12.4\%) patients died during hospitalisation; $8,924(25.1 \%)$ of them within the first $48 \mathrm{~h}$. In-hospital death rates differ by admission day of the week, as follows: Monday, $11.7 \%$; Tuesday, $12.0 \%$; Wednesday, $11.9 \%$; Thursday, $12.3 \%$; Friday, $12.6 \%$; Saturday, $13.0 \%$; and Sunday, $12.7 \%(\mathrm{p}<0.001)$. Compared with those seen on weekdays, those seen on weekends had a higher case fatality $(12.9 \%$ versus $12.1 \%$; OR 1.07 (95\% CI 1.04-1.10)). Mortality remained significantly higher after adjustment for demographic characteristics and the presence or absence of coexisting conditions (1.04 (1.021.07)) (table 3).

Analyses of patients with COPD as a main diagnosis showed the same differences in mortality between weekend and weekday admissions (OR 1.05 (95\% CI 1.01-1.10)). 


\begin{tabular}{|c|c|c|c|}
\hline $\begin{array}{l}\text { Chara } \\
\text { diseas } \\
\text { weeke }\end{array}$ & $\begin{array}{l}\text { teristics of c } \\
\text { e patients wi } \\
\text { nds and wee }\end{array}$ & $\begin{array}{l}\text { nic obstruct } \\
\text { a hospital ac } \\
\text { ays }\end{array}$ & $\begin{array}{l}\text { ulmonary } \\
\text { sion on }\end{array}$ \\
\hline $\begin{array}{l}\text { Patient } \\
\text { characteristics }\end{array}$ & Weekend & Weekday & $p$-value \\
\hline Admissions & $69770(24.1)$ & 219307 (75.9) & \\
\hline Age yrs & $74.23 \pm 13.23$ & $73.85 \pm 13.19$ & $<0.001$ \\
\hline Males & $48452(69.4)$ & $153617(70.0)$ & 0.03 \\
\hline \multicolumn{3}{|l|}{ Comorbidity CCI } & 0.02 \\
\hline 0 & $8160(11.7)$ & 24628 (11.2) & \\
\hline 1 & 27410 (39.3) & 85861 (39.2) & \\
\hline 2 & $17910(25.7)$ & 56859 (25.9) & \\
\hline$>2$ & $1625(23.3)$ & $51872(23.7)$ & \\
\hline \multicolumn{4}{|l|}{ Coexisting conditions } \\
\hline $\begin{array}{l}\text { Acute respiratory } \\
\text { failure }\end{array}$ & $38463(55.1)$ & $117044(53.4)$ & $<0.001$ \\
\hline $\begin{array}{l}\text { Chronic renal } \\
\text { disease }\end{array}$ & $3728(5.3)$ & $11611(5.3)$ & 0.651 \\
\hline Anaemia & $7223(10.4)$ & $22035(10.1)$ & 0.02 \\
\hline Heart failure & $12449(17.8)$ & 38935 (17.8) & 0.593 \\
\hline $\begin{array}{l}\text { Ischaemic heart } \\
\text { disease }\end{array}$ & $3642(5.2)$ & $11093(5.1)$ & 0.1 \\
\hline Cancer & $8238(11.8)$ & 26744 (12.2) & 0.006 \\
\hline Pneumonia & $20497(26.1)$ & $62589(27.8)$ & $<0.001$ \\
\hline Pulmonary embolism & $1425(2.0)$ & $4740(1.9)$ & 0.457 \\
\hline Dementia & $4292(6.2)$ & $12358(5.6)$ & $<0.001$ \\
\hline Diabetes & $16332(23.4)$ & $51260(23.4)$ & 0.850 \\
\hline Cigarette smoking & $9784(14.0)$ & $32211(14.7)$ & $<0.001$ \\
\hline Hypertension & 12449 (17.8) & 38935 (17.8) & 0.593 \\
\hline $\begin{array}{l}\text { Noninvasive } \\
\text { ventilation }\end{array}$ & $4296(1.8 \%)$ & $1237(1.7 \%)$ & 0.041 \\
\hline Length of stay days & $9.56 \pm 9.01$ & $9.84 \pm 8.90$ & $<0.001$ \\
\hline Mortality & 8982 (12.9) & $26562(12.1)$ & $<0.001$ \\
\hline Early mortality & $2440(3.5)$ & $6484(3.0)$ & $<0.001$ \\
\hline
\end{tabular}

Data are presented as $n(\%)$ or mean $\pm \mathrm{SD}$, unless otherwise stated. $\mathrm{CCl}$ : Charlson comorbidity index.

\section{Short-term mortality}

Analyses of deaths within 2 days of admission, rather than total in-hospital deaths, generally showed larger relative differences in mortality between weekend and weekday admissions. There was a small increase in mortality among patients admitted on a weekend (3.5 versus 3.0\%; OR 1.18 (95\% CI 1.13-1.25)). After adjustment for potential confounders, there was a $16 \%$ increase in early mortality among patients admitted on a weekend (OR 1.17 (95\% CI 1.12-1.23)) (table 3).

Analyses of 1-day in-hospital mortality showed a greater weekend effect for COPD patients (adjusted OR 1.39 (95\% CI 1.19-1.49)) when compared with 2-day or global in-hospital mortality. Analyses of 1-, 3- and 4-day in-hospital mortality showed similar differences between weekend and weekday admission of COPD patients (adjusted OR 1.18 (95\% CI 1.121.26) for 1-day mortality; 1.13 (95\% CI 1.09-1.18) for 3-day mortality; and 1.13 (95\% CI 1.08-1.17) for 4-day mortality).

\section{TABLE 2 Number and percentage of patients admitted each day of the week}

Patients admitted $\mathbf{n}(\%)$

Sunday
Monday
Tuesday
Wednesday
Thursday
Friday
Saturday
Total

$33955(11.7)$

$45667(15.8)$

$44815(15.5)$

$42928(14.9)$

$42296(14.6)$

$43601(15.1)$

$35815(12.4)$

$289077(100.0)$

\section{DISCUSSION}

This study has demonstrated that, among a large, representative population of patients admitted to the hospital for COPD exacerbation, there are differences in in-hospital death rates by the days of admission. Our study also showed that after adjustment for confounders, the mortality was higher among COPD patients admitted on weekends than among those admitted on weekdays. Some previous studies had not demonstrated the weekend effect in the mortality of COPD patients [15], because it is necessary to enrol a large sample to demonstrate this small (5\%), but significant and clinically relevant, difference. An excess of $5 \%$ in weekend mortality means than 887 (95\% CI 3471,387) of COPD patients die annually in Spain due to the weekend effect.

We found that the results of the adjusted analyses were similar to those of the crude analyses, suggesting that the findings were probably not due to unmeasured factors, such as the severity of illness. Moreover, analyses of deaths within the same day, the first day and 2 days after admission yielded even larger differences in mortality between weekend and weekday admissions in COPD patients, a finding that supports a true difference and would not be expected if our findings were due to a general increase in the severity of conditions among patients admitted at the weekend.

The problem with under-reporting of conditions such as hypertension, cigarette smoking or allergies, has been previously reported [18], and is one of the limitations of our study. However, there is no obvious reason why errors or underreported conditions should systematically vary between weekend and weekday admissions. The figure of cigarette smoking is not plausible in this COPD database; however, smoking does not influence the increased risk of mortality of patients admitted at the weekend.

The principal limitation of this study is that unmeasured confounders may have contributed to the reported differences in mortality between patients admitted on weekends and those admitted on weekdays. For example, the database does not include data on previous use of home oxygen therapy, admission to the intensive care unit, blood gas values or medications administered during hospitalisation. It is possible that differential administration of pharmacological agents could explain some of the observed differences between weekend and weekday admission. Furthermore, patients admitted on weekends 
TABLE 3 Association between chronic obstructive pulmonary disease characteristics and both short-term and overall mortality

\begin{tabular}{|c|c|c|c|c|}
\hline Characteristics & $\begin{array}{l}\text { Unadjusted OR for short-term } \\
\text { mortality }{ }^{\#}\end{array}$ & $\begin{array}{l}\text { Adjusted } \text { OR for short-term } \\
\text { mortality }\end{array}$ & $\begin{array}{l}\text { Unadjusted OR for overall } \\
\text { mortality }\end{array}$ & $\begin{array}{c}\text { Adjusted OR for overall } \\
\text { mortality }\end{array}$ \\
\hline Female & $1.37(1.31-1.43)$ & $1.14(1.11-1.20)$ & $1.28(1.27-1.31)$ & $1.13(1.11-1.16)$ \\
\hline \multicolumn{5}{|l|}{$\mathrm{CCl}$} \\
\hline 0 & 1 & 1 & 1 & 1 \\
\hline$>2$ & $1.1(1.01-1.16)$ & $1.17(1.09-1.25)$ & $1.54(1.49-1.90)$ & $1.74(1.68-1.82)$ \\
\hline Dementia & $2.67(1.51-2.84)$ & $1.97(1.84-2.11)$ & $2.95(1.85-3.06)$ & $2.11(2.04-2.20)$ \\
\hline Acute respiratory failure & $2.45(1.34-2.57)$ & $2.18(2.08-2.30)$ & $1.21(1.16-2.26)$ & $2.03(1.98-2.08)$ \\
\hline Pneumonia & $1.50(1.44-1.57)$ & $1.19(1.13-1.25)$ & $1.56(1.52-1.59)$ & $1.34(1.30-1.37)$ \\
\hline Pulmonary embolism & $1.76(1.57-1.98)$ & $1.53(1.35-1.72)$ & $1.57(1.47-1.68)$ & $1.49(1.39-1.60)$ \\
\hline Noninvasive ventilation & $1.09(0.94-1.27)$ & $1.14(0.98-1.33)$ & $1.42(1.32-1.53)$ & $1.55(1.43-1.67)$ \\
\hline
\end{tabular}

tended to have less neoplasic disease, which would be associated with lower mortality, and had slightly higher rates of acute respiratory failure, which would be associated with higher mortality. Our study does not account for deaths that occurred outside the hospital, which are more common on weekends than on weekdays, in some studies [8]. With the type of data used in this study, the interval from exacerbation to admission cannot be taken into account, and this is also a limitation. However, although small differences were noted in certain baseline characteristics between weekend and weekday admissions, they were included in the multivariate analysis, and differences in adjusted mortality were still observed. The increase in mortality persisted after adjustment for age, sex, CCI score and other potential confounders. We found that the results of the adjusted analyses were similar to the crude analyses, suggesting that the findings were probably not due to unmeasured factors, such as the severity of illness. Moreover, analyses of deaths within 2 days of admission yielded even larger differences in mortality between weekend and weekday admissions, a finding that supports a true difference and would not be expected if our findings were due to a general increase in severity of conditions among patients admitted on weekends.

Our findings have several possible explanations. Hospital staffing is reduced on Saturdays and Sundays, and fewer supervisors are present in the hospital at the weekend $[13,14]$. In addition, the level of physician coverage for patients also differs during the weekend in most hospital settings, and the weekend physician staff frequently provide coverage for other health professionals, and so might be less familiar with the patients under their care $[9,19]$. There is reduced accessibility to certain resources, such as laboratory, radiology, or pulmonary specialists, and weekend staff may be less familiar with noninvasive ventilation $[14,20]$. In COPD patients, the poorer prognosis may be linked to a shortage of pulmonary specialists, or specialised internists being on call at the weekend. A young emergency department physician may be more reluctant to begin noninvasive ventilation to assist in a situation of respiratory insufficiency, which has been shown to reduce hospital mortality and improve the prognosis [21]. Even small differences in clinical outcomes in patients with COPD could translate into substantial numbers of deaths for this patient population because of the large number of patients hospitalised with COPD each year [3]. Other plausible alternative explanations could be a delay in admission of patients during weekends. In addition, weekendrelated changes in diet, physical activity, environmental cigarette smoke, and exposure to infection $[2,22]$ could play a role in the type of COPD patients admitted during weekends.

In conclusion, COPD patients admitted at weekends showed poorer survival. Efforts should be made to increase the efficacy and decrease the fallibility of doctors during periods of short staffing. Although additional research is needed, electronic automated alarms designed to detect patients at higher risk or to ensure that physicians apply specific protocols for special patients could help in this task [23]. A recent study has provided empirical evidence that greater automation of a hospital's information systems may be associated with reductions in mortality, complications and costs [24]. Health information technology, such as electronic medical records, computerised provider order entry systems, and clinical decision support systems, have been reported to improve patient safety and quality of care, while lowering costs.

\section{STATEMENT OF INTEREST}

None declared.

\section{ACKNOWLEDGEMENTS}

The authors thank the Spanish Ministry of Health for granting permission to obtain the data.

\section{REFERENCES}

1 Bustamante-Fermosel A, De Miguel-Yanes JM, Duffort-Falco M, et al. Mortality-related factors after hospitalization for acute exacerbation of chronic obstructive pulmonary disease: the burden of clinical features. Am J Emerg Med 2007; 25: 515-522. 
2 Kinnunen T, Säynäjäkangas O, Keistinen T. Features of hospitalisations for acute exacerbation of COPD resulting in death. Monaldi Arch Chest Dis 2007; 67: 10-14.

3 Mannino DM. COPD: epidemiology, prevalence, morbidity and mortality and disease heterogenity. Chest 2002; 121: 121S-126S.

4 Barba Martín R, Marco Martinez J, Losa Emilia J, et al. Análisis de 2 Años de Actividad de Medicina Interna en los Hospitales del Sistema Nacional de Salud [Two-year analysis of internal medicine activity in the National Health Care System hospitals]. Rev Clin Esp 2009; 209: 459-466.

5 Wouters EF. Economic analysis of the confronting COPD survey: an overview of results. Respir Med 2003; 97: S3-S14.

6 Faustini A, Marino C, D'Ippoliti D, et al. The impact on risk-factor analysis of different mortality outcomes in COPD patients. Eur Respir J 2008; 32: 629-636.

7 Barba R, Losa JE, Velasco M, et al. Mortality among adult patients admitted to the hospital on weekends. Eur J Intern Med 2006; 17: 322-324.

8 Bell CM, Redelmeier DA. Mortality among patients admitted to hospitals on weekends as compared with weekdays. N Engl J Med 2001; 345: 663-668.

9 Cram P, Hillis SL, Barnett M, et al. Effects of weekend admission and hospital teaching status on in-hospital mortality. Am J Med 2004; 117: 151-157.

10 Kostis WJ, Demissie K, Marcella SW, et al. Weekend versus weekday admission and mortality from myocardial infarction. $N$ Engl J Med 2007; 356: 1099-1109.

11 Marco J, Barba R, Plaza S, et al. Analysis of the mortality of patients admitted to internal medicine wards over the weekend. Am J Med Qual 2010; 25: 312-318.

12 Saposnik G, Baibergenova A, Bayer N, et al. Weekends: a dangerous time for having a stroke? Stroke 2007; 38: 1211-1215.

13 Aiken LH, Clarke SP, Sloane DM, et al. Hospital nurse staffing and patient mortality, nurse burnout and job dissatisfaction. JAMA 2002; 288: 1987-1993.
14 Needleman J, Buerhaus $\mathrm{P}$, Mattke S, et al. Nurse-staffing levels and the quality of care in hospitals. $N$ Engl J Med 2002; 346: 1715-1722.

15 Clarke MS, Wills RA, Bowman RV, et al. Exploratory study of the "weekend effect" for acute medical admissions to public hospitals in Queensland, Australia. Intern Med J 2010; 40: 777-783.

16 Charlson ME, Pompei P, Ales KL, et al. A new method of classifying prognostic comorbidity in longitudinal studies: development and validation. J Chronic Dis 1987; 40: 373-383.

17 Deyo RA, Cherkin DC, Ciol MA. Adapting a clinical comorbidity index for use with ICD-9-CM administrative databases. J Clin Epidemiol 1992; 45: 613-619.

18 Borzecki AM, Wong AT, Hickey EC, et al. Identifying hypertension-related comorbidities from administrative data: whats the optimal approach? Am J Med Qual 2004; 19: 201-206.

19 Becker DJ. Do hospitals provide lower quality care on weekends? Health Serv Res 2007; 42: 1589-1612.

20 Bell CM, Redelmeier DA. Waiting for urgent procedures on the weekend among emergently hospitalised patients. Am J Med 2004; 117: 175-181.

21 Plant PK, Owen JL, Elliot MW. Early use of non-invasive ventilation for acute exacerbations of chronic obstructive pulmonary disease on general respiratory wards: a multicentre randomised controlled trial. Lancet 2000; 355: 1935.

22 Keatinge WR, Donaldson GC. Changes in mortalities and hospital admissions associated with holidays and respiratory illness: implications for medical services. J Eval Clin Pract 2005; 11: 275-281.

23 Burkle T, Baur T, Hoss N. Clinical pathways development and computer support in the EPR: lessons learned. Stud Health Technol Inform 2006; 124: 1025-1030.

24 Amarasingham R, Plantinga L, Diener-West M, et al. Clinical information technologies and inpatient outcomes. Arch Intern Med 2009; 169: 108-114. 